Economics Working Paper Series

2019/014

\title{
Speculative Bubbles in Segmented Markets: Evidence from Chinese Cross-Listed Stocks
}

\author{
Efthymios G Pavlidis and Kostas Vasilopoulos \\ The Department of Economics \\ Lancaster University Management School \\ Lancaster LA1 4YX \\ UK
} provided that full acknowledgement is given. 


\title{
Speculative Bubbles in Segmented Markets: Evidence from Chinese Cross-Listed Stocks
}

\author{
Efthymios G Pavlidis* ${ }^{\dagger}$ and Kostas Vasilopoulos ${ }^{\dagger}$ \\ ${ }^{\dagger}$ Department of Economics, Lancaster University Management School, Lancaster, UK
}

\begin{abstract}
We propose a novel approach for testing for rational speculative bubbles in segmented capital markets. The basic idea is that, under capital controls, heterogeneity of speculative expectations across international equity markets causes financial assets with identical cash flow promises to trade at different prices. Because these deviations from the law of one price inherit the properties of the speculative bubble process, they display periods of explosive dynamics and have predictive power for future movements in equity prices in sample. These two hypotheses can be examined empirically using sequential unit root tests and predictive regressions. An attractive feature of this approach for bubble detection is that it does not require the specification of a model for market fundamentals, thus mitigating the well-known joint hypothesis problem. The focus of the paper is on mainland Chinese companies that cross list shares in Hong Kong. China is an ideal setting for our analysis because of the significant restrictions on capital movements imposed by the authorities and the turbulent behaviour of its stock market over the last decades.
\end{abstract}

Keywords: speculative bubbles; law of one price; AH premium; recursive unit root tests; predictive regressions

JEL Classification: C22, C32, G15

${ }^{*}$ Correspondence to: Efthymios G. Pavlidis, Department of Economics, Lancaster University Management School, LA1 4YX, UK. E-mail: e.pavlidis@lancaster.ac.uk 


\section{Introduction}

China's stock market: A crazy casino (The Economist, May 26 ${ }^{\text {th }} 2015$ )

Since the re-opening of the Shanghai stock exchange (SSE) and the foundation of the Shenzhen stock exchange (SZSE) in the early 1990s, the Chinese stock market has experienced a remarkable growth. Starting from just a handful of listed companies in 1990 and a tiny market capitalization, it expanded to over three thousand firms in 2017 and a market capitalization of seven trillion dollars, ranking second worldwide behind the United States (Carpenter and Whitelaw, 2017). While the Chinese stock market has grown rapidly over the last decades, movements in Chinese share prices have been anything but tranquil, with spectacular price rallies followed by severe market crashes occurring in the 1990s, 2000s, and 2010s. Such extreme financial events appear difficult to explain using observed market fundamentals and have led to a consensus that speculative forces are in action in the Chinese stock market. Notably, in his 2001 speech, the preeminent Chinese economist Wu Jinglian compared China's stock market to a casino, that is manipulated by speculators and lacks a strong link to fundamentals. The casino term has since been adopted by the popular press to describe the overall behaviour of Chinese share prices. Given China's leading role in global economic growth and investment, the presence of speculative dynamics, bubbles, in the country's capital allocation system constitutes a topic of increasing significance.

In general, testing for speculative bubbles in financial markets is confounded by the fact that the fundamental value of financial securities is unobserved. Early studies have attempted to address this issue by utilizing observed variables, such as dividends, to estimate intrinsic values. A major drawback of such direct approaches is that they depend crucially on the strong and, in most cases, unrealistic assumption that the true data generating process for fundamentals is known. As argued by several researchers, model misspecification or omitted variables can lead to false inference in favour of bubbles, rendering direct approaches invalid (Hamilton and Whiteman, 1985; Flood and Garber, 1994, Gürkaynak, 2008). To circumvent this problem, more recent studies have employed indirect approaches that exploit information about market fundamentals incorporated in derivative prices or survey data (Pavlidis et al., 2017, 2018). These studies show that periodically collapsing bubbles create a wedge between actual realizations of future spot prices and market expectations which, under general conditions, depends solely on the bubble process. As an implication, rather than using estimates of intrinsic asset values to assess the presence of speculative bubbles, researchers can examine the dynamics of the difference between actual future spot prices and market expectations. Unfortunately, indirect approaches based on future prices or survey data cannot be applied in the case of China because derivative markets are at an early stage of development and survey data on market expectations that cover periods long enough to allow a proper econometric analysis do not exist ${ }_{1}^{1}$

\footnotetext{
${ }^{1}$ Equity warrants were briefly introduced in China in 2005-8 (Liu et al. 2014). By examining the behaviour of the warrants market during this period, Xiong and Yu (2011) provide strong evidence in favour of speculative dynamics. Specifically, they show
} 
In this paper, we propose an alternative approach for testing for rational speculative bubbles that makes use of the unique trading features of Chinese cross-listed securities. There is a large number of companies incorporated in mainland China that simultaneously issue A shares on SSE or SZSE, and H shares on the Stock Exchange of Hong Kong (SEHK). For a given issuer, these two types of shares have identical voting rights and exchange-rate-adjusted dividend payments (i.e., they have the same fundamentals) but differ in terms of their accessibility by different groups of investors. Prior to the introduction of the Stock Connect scheme in 2015, Chinese mainland investors could easily access A but not $\mathrm{H}$ shares, while international and Hong Kong investors could readily access $\mathrm{H}$ but not A shares because of strict government regulations. The segmentation of A- and H-share markets implied that price valuations of the same security could differ across geographical locations without giving rise to arbitrage opportunities (Chen and Knez, 1995; Froot and Dabora, 1999; Lamont and Thaler, 2003). The main idea of the present paper is that, in this setting with limits to arbitrage, differences in speculative trading in Chinese mainland and Hong Kong can lead to distinct bubbles processes in A- and H-share markets. As a consequence, share prices of cross-listed companies can diverge despite having the same underlying fundamentals.

To demonstrate the theoretical implications of different speculative dynamics in A- and H-share markets, we adopt a standard asset-pricing model with rational, risk-neutral investors and consider a periodically collapsing bubble process in the market for A but not for $\mathrm{H}$ shares. We show that, in this framework, the A-H price differential displays two characteristic properties when the bubble erupts. First, the price differential grows (in expectation) at an exponential rate, thus displaying explosive dynamics and, second, it has predictive content for future changes in A-share prices. These two properties can be examined empirically to test for speculative bubbles by exploiting recent advances in recursive unit root tests and in predictive regression tests with persistent regressors.

For our empirical application, we use data on the Hang Seng AH Premium Index and on a panel of 27 cross-listed companies spanning the period from January 2006 to December 2016. By employing the popular Generalized Supremum Augmented Dickey Fuller (GSADF) of Phillips et al. (2015a|b) and its panel version, we show that A-H price differentials display episodes of explosive dynamics. These episodes are relative short and coincide with periods commonly considered to be characterized by speculative bubbles. Namely, the Chinese stock market frenzy of 2007 and the Chinese Stock market crash of 2014-2015. A similar conclusion is reached by looking at the predictive regression results, which indicate periods of insample predictability, again, during 2007 and 2014-15. Overall, in line with the casino hypothesis, our findings support the presence of speculative dynamics in the Chinese stock market.

The presence of distinct bubble processes in mainland China and Hong Kong provides a possible explanation for one of the most intriguing puzzles in finance: the large and highly persistent share price that the price of many put warrants with long maturities exceeded both the upper bound given by the strike price and the more conservative fundamental value implied by the Black and Scholes model. 
deviations of Chinese cross-listed companies (Fernald and Rogers, 2002, Carpenter and Whitelaw, 2017). In addition to speculation, a number of other factors have been put forth in the literature to explain foreign share discounts, such as different attitudes toward risk, information asymmetries, changes in exchange rate expectations, liquidity and transaction costs (Wang and Jiang, 2004, Chan et al., 2008; Chung et al., 2013). As a final exercise, we use a dynamic panel probit methodology to investigate whether such factors can explain the identified episodes of exuberance in A-H price differentials.

The rest of the paper is structured as follows. Section 2 provides an overview of the institutional background of Chinese stock markets. Section 3 outlines the theoretical framework and describes the proposed bubble detection methods. The following section deals with the empirical application of these methods to A-H cross-listed shares. The same section provides a robustness exercise based on American Depository Receipts, and also presents the results of the dynamic panel probit analysis. The final section concludes.

\section{Institutional Background}

China's modern stock market opened only in the early 1990s with the re-establishment of SSE on November 26, 1990 and the foundation of the SZHE on December 1, 1991. Upon their opening, SSE listed eight companies and had a market capitalization of 1.2 billion renminbi (RMB), and SZHE listed six companies with a total share capital of 273 million RMB. By 2016, the number of listings in SSE and SZHE increased to 3,134 firms and their combined market capitalization reached 51 trillion RMB, which corresponded to 68 percent of the country's gross domestic product.

There are two types of tradable shares issued by Chinese firms listed on SSE and SZHE, the so-called A and B shares. The market for A shares is by far the largest, accounting for the lion's share of trading volume and market capitalization. A shares are quoted in domestic currency (RMB) and, until recently, were primarily traded by mainland Chinese citizens due to strict capital controls imposed by the Chinese authorities ${ }^{2}$ B shares, on the other hand, are traded in foreign currency (US dollars in Shanghai and HongKong dollars in Shenzhen) and were limited to foreign investors until February 2001, when China Securities Regulatory Commission (CSRC) permitted their purchase by mainland citizens via the secondary market.

Since 1993, Chinese firms can also list shares on stock exchanges outside mainland China to raise capital from abroad. Due to its geographical proximity and extensive socio-economic links to the mainland,

\footnotetext{
${ }^{2}$ During our sample period, China implemented a number of schemes aiming to gradually open its capital market to overseas investors. In 2002, the Qualified Foreign Institutional Investor (QFII) program was launched, which allowed overseas financial institutions that met a set of admission requirements to invest in Chinas securities markets subject to quotas. In 2011, a second scheme, the Renminbi QFII (RQFII), was jointly established by the CSRC, the Peoples Bank of China, and the State Administration of Foreign Exchange (SAFE). The scheme allowed subsidiaries of domestic financial institutions in Hong Kong to invest in mainland stock markets. As of February 2016, 279 foreign institutions had been granted QFII licenses and 158 institutions RQFII licenses. The total QFII and RQFII quotas were 80.795 billion US dollars and 471.425 billion RMB, respectively, which represented a small fraction of total market capitalization. (see http://english.sse.com.cn/investors/qfii/listandquota/).
} 
the most popular location is Hong Kong. Compared to SSE and SZHE, the Stock Exchange of Hong Kong (SEHK) constitutes a more advanced financial market, it has adopted financial reporting standards that are in alignment with the IFRS since 2005, and it is open to foreign investors. In 2016, 241 Chinese firms issued shares in SEHK with a market capitalization exceeding 24 trillion Hong-Kong dollars. This type of shares, referred to as $\mathrm{H}$, is subject to the Hong Kong Exchanges and Clearing Limited listing requirements, and are quoted and traded in Hong Kong dollars. Analogously to the market for A shares, investors residing in mainland China had very limited access to the market for $\mathrm{H}$ shares until 2015 due to tight restrictions on capital movements $\mathrm{S}^{3}$

A key feature for our analysis is that a number of Chinese companies issue both A shares in mainland China and $\mathrm{H}$ shares in Hong Kong. Apart from their trading location, these cross-listed securities are identical. They have the same legal rights and the same claims to exchange-rate adjusted dividends. Moreover, cross-listed Chinese companies are required to disclose the same information to local and overseas investors (Jia et al. 2017). Thus, in the absence of market frictions, A and $\mathrm{H}$ shares should trade for the same price. However, due to the segmentation of $\mathrm{A}$ and $\mathrm{H}$ markets, deviations from the law of one price are typical, with A shares usually trading at a premium.

\section{INSERT TABLE 1}

A potential explanation for the documented A-H price disparities is investor heterogeneity between markets. On the one hand, the market for A shares is dominated by local, retail investors. These investors account for more than 80 percent of the trading volume and, as survey evidence suggests, are less experienced than US investors and younger, with more than half being under 45 years of age (see, Gan et al., 2014, Feng and Seasholes, 2003, and the 2013 CSRC securities report). On the other hand, retail investors comprise only a small part of the Hong Kong market (26 percent during our sample period), with most of the trading volume being generated by institutional investors (61 percent). Trading from overseas investors (mainly from the United States and Europe) is also substantial, accounting for 42 percent of the total volume (see Table 1). Mei et al. (2005), among others, argue that, because of their type and age composition, stock market investors in mainland China are more likely to engage in intense speculative trading.

\footnotetext{
${ }^{3}$ In 2006, the Qualified Domestic Institutional Investor (QDII) program was launched which provided limited opportunities for mainland investors to access overseas markets, including Hong Kong, via CSRC approved financial institutions. As of December 2015, 132 institutions had been granted QDII qualification, and SAFE had approved investment quotas of 90 billion US dollars. In November 2014, the Shanghai-Hong Kong Stock Connect program was launched. Under this program, SSE and SEHK established mutual order-routing connectivity which enabled mainland Chinese and international/Hong-Kong investors to trade specific securities listed in SEHK and SSE, respectively. The program is open to exchange participants who satisfy certain eligibility requirements, and covers all cross-listed shares. Initially, trading was subject to daily and aggregate quotas. The northbound aggregate quotas were set at 300 billion RMB, while the southbound aggregate at 250 billion RMB. Aggregate quotas were abolished in August 2016, but daily quotas are still in place. A similar channel that links the markets of Shenzhen and Hong Kong, the Shenzhen-Hong Kong Stock Connect, was launched in December 2016.
} 


\section{Rational Bubbles: Theory and Econometric Tests}

We begin our analysis with a standard endowment economy in which rational, infinitely-lived investors derive utility from personal consumption (Diba and Grossman, 1988, Gürkaynak, 2008). In this economy, the representative investor's objective is to

$$
\max \mathrm{E}_{\tau} \sum_{\tau=t}^{\infty} \beta^{\tau-t} u\left(C_{\tau}\right)
$$

where $C_{\tau}$ denotes the level of consumption at period $\tau, E_{\tau}$ is the rational expectations operator conditional on all available information at time $\tau$, and $\beta$ is a discount factor that is restricted to take values in $(0,1)$ so that time preferences are positive. The instantaneous utility function, $u(\cdot)$, is assumed to be concave, increasing in $C_{\tau}$, and continuously differentiable.

At each time period, $\tau$, the investor is faced with a budget constraint. She receives an endowment $y_{\tau}$ which can be instantly consumed or used to purchase dividend-paying shares, $s_{\tau}$, in order to smooth future consumption. Letting $P_{\tau}$ denote the price of a share in units of the consumption good and $D_{\tau}$ the dividend payment, the budget constraint faced by the investor is given by

$$
C_{\tau} \leq y_{\tau}+\left(s_{\tau+1}-s_{\tau}\right) P_{\tau}+D_{\tau} s_{\tau}
$$

The first order condition for the investor's utility maximization problem specified by (1) and (2) is given by

$$
P_{t} u\left(C_{t}\right)=\beta \mathrm{E}_{\tau}\left[\left(P_{t+1}+D_{t+1}\right) u^{\prime}\left(C_{t+1}\right)\right] .
$$

Intuitively, the above Euler equation states that for a time-path of $s$ to be optimal, an investor cannot become better off by selling or buying a share at time $t$ and reversing the transaction at time $t+1$. By assuming that financial and goods markets clear and normalizing the number of existing shares to unity, Equation (3) can be rewritten as

$$
E_{t}\left[q_{t+1}\right]-\beta^{-1} q_{t}=-E_{t}\left[u^{\prime}\left(y_{t+1}+D_{t+1}\right) D_{t+1}\right]
$$

where $q_{t} \equiv P_{t} u^{\prime}\left(y_{t}+D_{t}\right)$. The general solution to this first order stochastic difference equation is given by

$$
q_{t}=F_{t}+B_{t}
$$

where the first term of the RHS is referred to as the market fundamentals component because it depends on the present value of all future dividends and the marginal utilities of consumption, $F_{t}=\sum_{j=1}^{\infty} \beta^{j} E_{t}\left[u^{\prime}\left(y_{t+j}+\right.\right.$ 
$\left.\left.D_{t+j}\right) D_{t+j}\right]$; while, the second term is a rational bubble component that satisfies the condition

$$
E_{t}\left[B_{t+1}\right]=\beta^{-1} B_{t} .
$$

In the empirical literature on rational bubbles, $B_{t}$ is usually viewed to be driven by variables that are exogenous to the valuation process. Moreover, it is often assumed that utility is linear, which implies risk neutrality and constant marginal utility. Under this latter assumption, the general solution to (4) simplifies to the textbook asset pricing equation

$$
P_{t}=F_{t}+B_{t}=\sum_{j=1}^{\infty} \beta^{j} E_{t}\left[D_{t+j}\right]+B_{t},
$$

which links the current stock price to the bubble process $B_{t}$ and to a market-fundamentals component that equals the discounted value of expected future dividends.

The above analysis has important implications for econometric tests for rational speculative bubbles. By condition (6), if a bubble exists then it will grow, in expectation, geometrically at the rate of $\beta^{-1}-1$. It follows from Equation (7) that the stock price will display explosive dynamics and diverge from its fundamental value over time 4 This prediction has motivated a plethora of studies that employ non-stationarity tests to examine the presence of speculative bubbles in financial markets. Some studies have applied unit root tests to stock prices and price-to-fundamentals ratios (such as stock prices to dividends). Others have examined the existence of cointegrating relationships between prices and observed market fundamentals. The main drawback of such direct approaches is that they rely on strong assumptions about the data generating process for market fundamentals which are difficult to verify in practice. Specifically, tests on raw prices implicitly assume that the fundamental component in (7) does not display explosive dynamics in sample. Whilst, tests that control for market fundamentals by using observed economic and financial variables are subject to model misspecification and omitted-variable problems. As argued by several researchers, these deficiencies can lead to false inference (Gürkaynak, 2008).

\subsection{Cross-Listed Securities}

Consider an extension of the above framework to two segmented, but otherwise identical economies, A and $\mathrm{H}$, in which investors trade shares of the same storable asset locally. In this setting, there is an asset

\footnotetext{
${ }^{4}$ The increasing difference between actual and intrinsic asset values arises because of investors' expectation to sell the asset at an even higher price in a future date. Note, however, that these large, expected capital gains do not imply arbitrage opportunities since they are already priced in the market. That is, the evolution of asset prices satisfies the requirement of market efficiency by construction.
} 
pricing equation for each economy given by

$$
P_{t}^{i}=F_{t}^{i}+B_{t}^{i}
$$

with $i=A, H$. Because investors are entitled to the same stream of dividend payments irrespective of their location, their valuations for the market fundamental components of A- and $\mathrm{H}$-share prices satisfy $F_{t}^{A}=F_{t}^{H}$. However, there are no forces that guarantee equality of the bubble components $B_{t}^{A}$ and $B_{t}^{H}$. This is so because arbitrage between markets is not feasible and market efficiency dictates that $\left\{B_{t}^{i}\right\}_{t=0}^{\infty}$ can be any sequence of random variables that satisfies condition (6). Thus, allowing for speculative bubbles in financial markets gives rise to the possibility of non-unique asset price paths for $\mathrm{A}$ and $\mathrm{H}$ shares,

$$
P_{t}^{A}-P_{t}^{H}=B_{t}^{A}-B_{t}^{H}
$$

and can lead to violations of the law of one price. The above expression lies in the heart of our analysis. It suggests that the price differential between $\mathrm{A}$ and $\mathrm{H}$ shares, first, does not depend on market fundamentals and, second, it displays the same behaviour as the difference in bubble sequences. As long as $B_{t}^{A}$ and $B_{t}^{H}$ are not co-explosive, the price differential will exhibit explosive dynamics (see Nielsen, 2010). Therefore, one can test for the presence of distinct speculative bubbles, while remaining agnostic about the intrinsic value of the asset, by simply running right-tailed unit root tests on $P_{t}^{A}-P_{t}^{H}$.

Recursive Unit Root Tests The property that $P_{t}^{A}-P_{t}^{H}$ is explosive when $B_{t}^{A}$ and $B_{t}^{H}$ do not co-explode holds irrespective of the type of speculative bubble. The simplest scenario is that of a linear AR(1) process for $B_{t}^{A}$

$$
B_{t+1}^{A}=\beta^{-1} B_{t}^{A}+\epsilon_{t+1}
$$

where $\epsilon_{t+1} \sim \operatorname{iid}\left(0, \sigma_{\epsilon}^{2}\right)$, and no bubbles in the market for $\mathrm{H}$ shares, $B_{t}^{H}=0$. For the case of the Chinese market, it is more realistic to presume that bubbles, if they exist, are periodically collapsing. For expositional purposes, we focus on the periodically-collapsing bubble proposed by Blanchard (1979)

$$
B_{t+1}^{A}=\left\{\begin{array}{cl}
\frac{1}{\beta \pi} B_{t}^{A}+\epsilon_{t+1}, & \text { with prob. } \pi \\
\epsilon_{t+1}, & \text { with prob. } 1-\pi .
\end{array}\right.
$$

This process switches between two states. In the first state, it grows geometrically at the higher than average rate of $1 /(\beta \pi)-1$, whilst in the second state it collapses to a white noise. In expectation, the growth rate of $B_{t}^{A}$ equals $\beta^{-1}-1$ and, therefore, Equation 11 s satisfies (6). By resembling the behaviour of the bubble process, the price differential

$$
P_{t}^{A}-P_{t}^{H}=B_{t}^{A}
$$


also alternates between an explosive and a stationary state. As will be shown in the following section, this behaviour is in line with the price rallies and subsequent collapses that have characterized the A-H premium index over the last decades.

From an empirical perspective, the presence of boom-bust dynamics in $P_{t}^{A}-P_{t}^{H}$ implies that standard unit root tests based on linear, time-invariant regression equations may display extremely low power to detect bubbles. A number of studies illustrate that such tests frequently lead to finding spurious stationarity even though asset prices driven by periodically-collapsing bubbles are inherently explosive (see, e.g., Evans, 1991). To deal with this shortcoming, in this paper we employ the GSADF test of Phillips et al. (2015a b) and its panel version proposed by Pavlidis et al. (2016). The GSADF test has a number of attractive features. First, due to its recursive nature, it is consistent with multiple changes in regime. Second, it displays accurate size and good power properties and in many cases is superior to alternative tests for periodically-collapsing bubbles (for simulation evidence, see Phillips et al., 2015a, and Homm and Breitung, 2012). And third, it permits identification of the periods during which the series under examination displays explosive dynamics. The panel version, on the other hand, introduces a rich specification, that captures the heterogeneity and cross-sectional dependencies of constituent series, in order to test for overall exuberance. By doing so, it can lead to substantial power gains in comparison to univariate unit root procedures applied to aggregate series (Pavlidis et al. 2019). A description of the GSADF and panel GSADF tests can be found in Appendix A.1.

Rolling Predictive Regressions The presence of distinct asset price bubbles has also implications for predictability tests on stock prices. Consider the following predictive regression

$$
P_{t+1}^{A}-P_{t}^{A}=\alpha_{0}+\alpha_{1}\left(P_{t}^{A}-P_{t}^{H}\right)+u_{t+1}
$$

where $\alpha_{0}$ and $\alpha_{1}$ are regression coefficients, and the error term $u_{t+1} \sim \operatorname{iid}\left(0, \sigma_{u}^{2}\right)$. In the absence of speculative bubbles and under risk neutrality, the efficient market hypothesis postulates that movements in stock prices are unpredictable and, therefore, the value of the slope coefficient in 13 is continuously equal to zero. However, this prediction may fail in the presence of distinct bubbles. To illustrate this point most simply, let fundamentals follow a random walk process, $F_{t+1}=F_{t}+v_{t+1}$, and consider again the case of an ongoing bubble in the market for $\mathrm{A}$ shares but no bubble in the market for $\mathrm{H}$ shares. The least squares estimate for the slope coefficient in regression (13) is

$$
\widehat{\alpha}_{1}=\frac{\widehat{\operatorname{cov}}\left(P_{t+1}^{A}-P_{t}^{A}, P_{t}^{A}-P_{t}^{H}\right)}{\widehat{\operatorname{var}}\left(P_{t}^{A}-P_{t}^{H}\right)} .
$$


We have already obtained an expression for the regressor in (14), see Equation (12). Using Equation (11), we can also obtain the following expression for the regressand

$$
P_{t+1}^{A}-P_{t}^{A}=\frac{1-\pi}{\beta \pi} B_{t}^{A}+\epsilon_{t+1}+v_{t+1} .
$$

Substituting (12) and (15) into the formula for the least-squares coefficient yields

$$
\widehat{\alpha}_{1}=\frac{1-\pi}{\beta \pi}+\frac{\widehat{\operatorname{cov}}\left(\epsilon_{t+1}, B_{t}^{A}\right)}{\widehat{\operatorname{var}}\left(B_{t}^{A}\right)}+\frac{\widehat{\operatorname{cov}}\left(v_{t+1}, B_{t}^{A}\right)}{\widehat{\operatorname{var}}\left(B_{t}^{A}\right)} .
$$

Because the vector of future shocks $\left(\epsilon_{t+1}, v_{t+1}\right)$ is orthogonal to $B_{t}^{A}$, the plim of $\widehat{\operatorname{cov}}\left(\epsilon_{t+1}, B_{t}^{A}\right) / \widehat{\operatorname{var}}\left(B_{t}^{A}\right)$ and of $\widehat{\operatorname{cov}}\left(v_{t+1}, B_{t}^{A}\right) / \widehat{\operatorname{var}}\left(B_{t}^{A}\right)$ are zero. Therefore, as the bubble erupts

$$
\operatorname{plim} \widehat{\alpha}_{1}=\frac{1-\pi}{\beta \pi}>0,
$$

and price movements in A shares become predictable. Note, however, that this ex post predictability cannot be exploited in real time by investors, who rationally price A shares by attaching a non-zero probability to the bubble bursting, and therefore it does not imply rejection of market efficiency. Note also that, in the absence of bubbles, explosive fundamentals cannot cause $\alpha_{1}$ to deviate from zero since in this case the regressor will be fixed at $P_{t}^{A}-P_{t}^{H}=0$.

The above analysis suggests that, if the null of non-explosive dynamics in $P_{t}^{A}-P_{t}^{H}$ is rejected, then researchers can further examine the presence of speculative bubbles by sequentially testing the hypothesis of no predictability, $H_{0}: \alpha_{1}=0$, against the one-sided alternative $H_{1}: \alpha_{1}>0$. An issue of concern in this framework is that the predictor in regression (13) is highly persistent under the alternative hypothesis. As a consequence, the slope coefficients $\alpha_{1}$ follows a non-standard limiting distribution, and results based on conventional inference methods can be misleading (Phillips, 2014). Several methods have been proposed in the literature to draw valid statistical inference in this setting, such as the efficient $Q$-test of Campbell and Yogo (2006), the conditional likelihood approach of Jansson and Moreira (2006), the nearly optimal test of Elliott et al. (2015), and the bootstrap procedures of Kilian (1999) and Kilian and Taylor (2003). We adopt a rolling-window approach that consists of sequentially estimating predictive regressions and drawing statistical inference using the IVX instrumentation method of Phillips and Magdalinos (2009), Phillips and Lee (2013), and Kostakis et al. (2015). The IVX method is particularly attractive in this setting because it allows robust chi-square inference for a wide range of AR processes, from stationary to mildly explosive. For a description of the IVX testing procedure, the interested reader is referred to Appendix A.2. 


\section{Empirical Results}

In this section, we apply the above bubble detection methods to data on Chinese A-H twin shares. We also provide two robustness checks. The first examines Chinese American Depository Receipts traded in the New York Stock Exchange, and the second explores the ability of sources, other than speculative bubbles, to explain episodes of exuberance in $\mathrm{A}$ and $\mathrm{H}$ share price differences.

\subsection{A and H Shares}

Data For our main empirical analysis, we employ the Hang Seng AH premium index, and a balanced panel of 27 Chinese companies simultaneously listed on SEHK and SSE or SZHE. The data are downloaded from Thomson Reuters Datastream and cover the period from the first week of January 2006 to the last week of December 2016 5 The reason for setting the start date at January 2006 is twofold. On the one hand, this choice allows us to examine the Chinese stock market frenzy of 2007 and, on the other, we avoid potential biases related to, first, the A-share market reforms that occurred in April 2005 and, second, the change in the exchange-rate regime that took place in July of the same year ${ }^{6}$ With regard to the data frequency, the use of weekly prices enables us examine a large sample size ( $T=575$ observations), which may lead to substantial power gains in detecting periodically-collapsing bubbles, especially if these are short-lived.

Table 2 reports the list of companies together with their stock ticker, the stock exchange on which they are listed, and the corresponding market sector. As can be seen from the table, the majority of shares (23 out of 27) are traded on SSE, which accounts for the largest share of total market capitalization in mainland China. Furthermore, the sample spans all but three stock market sectors, from energy and materials to utilities, health care and information technology. From this perspective, the sample is quite representative of the market.

\section{INSERT TABLE2}

The three sectors not covered in our analysis are communications, financial, and real estate. Regarding the latter, China has experienced a spectacular real estate boom during the last decades. Fang et al. (2016) show that real estate prices in the four most developed metropolitan areas (Beijing, Shanghai, Shenzhen,

\footnotetext{
${ }^{5}$ The entire population of companies that listed both A and $\mathrm{H}$ shares throughout our sample period is 29 . We have discarded two companies, Luoyang Glass and Hisense Kelon Electrical Holdings, due to the large number of missing observations, which exceeds $15 \%$ of the sample size. For the remaining companies, for which the percentage of missing data is small (less than $6 \%$ ), we have replaced missing data with the latest available observation.

${ }^{6}$ On the 29th of April 2005, the Chinese government implemented the Split Share Structure Reform which led to a substantial reduction in the number of state owned non-tradable shares. On the 21st of July 2005, China abandoned its peg to the US dollar, which caused an immediate appreciation to 8.11 RMB per US dollar. Since then, China has adopted a managed floating exchange rate with reference to a basket of foreign currencies.
} 
and Guangzhou) grew by 13 percent per annum from 2003 to 2013; and Wu et al. (2015) find that real land prices in 35 major Chinese cities increased by a factor of five for a sample period similar to ours. The sheer magnitude of these price changes makes the Chinese real estate boom even more spectacular than the one experienced by the US in the 2000s, and has raised concerns about the presence of speculative dynamics in the sector (Glaeser et al., 2017; Chen and Wen, 2017). In line with these concerns, several studies provide evidence in favour of bubble-type dynamics in China's real estate market (Zhi et al., 2019; Mao and Shen, 2019). Hence, if anything, the omission of real estate from our analysis may bias the results in favour of the no-bubble null hypothesis.

Summary Statistics Table 3 presents descriptive statistics (means, standard deviations, minimum and maximum values, and AR(1) coefficient estimates) of the A- to $\mathrm{H}$-share price ratios for the 27 cross-listed companies. To allow meaningful comparisons between markets, A-share prices are converted to Hong-Kong dollars. Two stylized facts about the size and the dynamics of A-H price disparities emerge. The first is that A shares typically sell at a premium relative to $\mathrm{H}$ shares. As is evident from Columns 2 and 4 of Table 3 , for the vast majority of companies, this premium is on average substantial, and can reach extreme values in parts of the sample. A prime example is Sinopec Oilfie, whose A shares traded at almost three times the price of $\mathrm{H}$ shares on average, and at slightly less than nine times the price of $\mathrm{H}$ shares in October 2008. The second fact that emerges is that A-H price ratios are highly persistent, with AR(1) coefficient estimates very close to unity. The above well-documented facts are difficult to reconcile with standard asset-pricing models, giving rise to the so-called A-H premium puzzle.

\section{INSERT TABLE 3 \& Figure 1}

The two stylized facts are also apparent when looking at the aggregate behaviour of A- and $\mathrm{H}$-share prices. Figure 1 shows the evolution of the Hang Seng AH premium index over time. This index measures the price premium/discount of $\mathrm{A}$ shares over $\mathrm{H}$ shares for the largest and most liquid cross-listed Chinese companies. Similarly to individual companies, the index typically takes values above its parity value of 100, averaging around 120 and reaching a maximum of 195 in 2008. The index is also highly persistent, displaying extraordinary long swings. Interestingly, the most notable AH premium rallies coincide with the two Chinese stock market 'bubbles': the market frenzy of 2007 and the period preceding the market crash of 2015. Given that the AH premium reflects deviations of asset prices from fundamentals, Figure 1 hints that the boom episodes in mainland China were driven by speculative trading.

Econometrics Results To formally examine the existence of speculative bubbles in the Chinese stock market, we run standard ADF and GSADF tests on the AH premium index and on the A-H price differentials 
for the 27 cross-listed companies. Following the recommendation of Phillips et al. (2015a b), we choose a short lag length, $k=1$, and set the minimum window size in the recursive GSADF procedure by using the rule of thumb $r_{0}=0.01+1.8 / \sqrt{T}$. Overall, the unit root test results provide several new insights about the integration properties of the series.

\section{INSERT TABLE 4}

Looking at the GSADF test statistic for the AH index and the panel GSADF statistic for the group of companies, presented in Table 4, we observe that the null hypothesis of no explosive behaviour can be rejected by both tests at all conventional significance levels. Thus, there is strong evidence of speculative bubbles in A-H share price differentials at the aggregate level. Although informative about the overall behaviour of the Chinese stock market, this finding does not shed light on whether bubbles are widespread across cross-listed companies. This is so because both the univariate and the panel GSADF tests can, in principle, reject the null even if a single constituent series displays exuberance 7 However, the results for the disaggregate data suggest that this is not the case. From the 27 cross-listed securities, 21 have statistically significant GSADF statistics at the one percent significance level, 23 at the five percent, and 24 at the ten percent. The conclusion that emerges is that speculative bubbles are prevalent across companies.

Another point that is worth noting is that, although the majority of GSADF statistics exceed the 95 percent critical value, the ADF statistics fail to do so. These findings are not inconsistent. As aforementioned, standard unit root tests, including the ADF, have extremely low power in detecting speculative bubbles which collapse in sample. Hence, taken together, the ADF and GSADF test results imply that A-H price differences display explosive dynamics during parts of, but not the entire, sample.

\section{INSERT FIGURES 2 \& 3}

To identify these periods of exuberance, we start by plotting the Backward Supremum ADF (BSADF) statistics for the A-H premium index, and the panel BSADF statistics for the 27 cross-listed companies together with their corresponding 95 percent critical value sequence in Figure 2 . A comparison of the test statistics with their critical values indicates that speculative bubbles occurred in 2007 and 2014-15. This conclusion is supported further by the results for individual companies. Figure 3 shows the periods of exuberance for each of the 24 cross-listed securities that have statistically significant GSADF statistics at

\footnotetext{
${ }^{7}$ For the univariate GSADF test, this property follows from the fact that the combination of the explosive constituent series with other unit root and/or stationary processes results in an explosive $\mathrm{AH}$ index, and for the panel test, it is a direct implication of the alternative hypothesis of at least one of the elements of the panel displaying explosive dynamics.
} 
the five percent level. As is evident from the figure, the episodes of exuberance are clustered around 2007-08 and 2014-15. The fact that bubble episodes are highly synchronized across companies points to the existence of a market-wide speculative factor that drove A-share prices to diverge from their fundamental values, and led to the stock market frenzy of 2007 and the market crash of 2014-15. The presence of such a factor is also in accordance with previous studies which show that changes in foreign share discounts are highly correlated with movements in the market they trade (Froot and Dabora, 1999).

Having established the presence of explosive dynamics in A-H twin share prices, we run rolling predictive regressions of the form given by Equation (13). To allow direct comparisons with the unit root test results, the rolling window size is set equal to the minimum window size $r_{0}$. Figure 4 shows the periods of predictability for each of the cross-listed securities in our sample. In accordance with the pattern of the BSADF statistics, we observe that the majority of IVX statistics become positive and statistically significant in 2007 and in 2014-15. Thus, as suggested by the theoretical analysis of Section 3 , A-H price differences have predictive content for future movements in A-share prices during periods of exuberance. Overall, the above results provide novel evidence in support of speculative bubbles in China's stock market.

\subsection{Chinese American Depository Receipts}

As a robustness check, we repeat the above analysis using a subset of our sample of Chinese companies for which American Depository Receipts (ADRs) are traded on the New York Stock Exchange. An ADR represents a bundle of $\mathrm{H}$ shares held in trust by a U.S. depository bank. On the one hand, these securities make it easier for U.S. investors to trade shares of companies incorporated outside the U.S. and, on the other, they provide a source of capital for China. Like A and $\mathrm{H}$ shares, ADRs entitle investors to the same exchange-rate-adjusted dividend payments and capital gains. However, contrary to A and $\mathrm{H}$ shares, limits to arbitrage between Hong Kong and the U.S. market are far less constraining. If an ADR sells at a premium, a financial intermediary can purchase $\mathrm{H}$ shares in Hong Kong, create a new ADR, and make an instant profit (Lamont and Thaler, 2003). Thus, arbitrage should restrict ADR and H-share prices from diverging due to speculation, but not ADR and A-share prices.

\section{INSERT TABLE[5, FIGURES 5 \& 6}

Our empirical results are in line with this hypothesis. Starting with the unit root test statistics presented in Table 5, we observe that the univariate GSADF and panel GSADF tests always fail to reject the null of non-explosive dynamics in ADR-H price differentials. On the contrary, there is strong evidence in favour of explosive dynamics for A-ADR price pairs, with all test statistics being significant at the one percent significance level. The results for the BSADF statistics, summarized in Figure 5, indicate that the periods 
of exuberance in the latter series are again synchronized, taking place in 2007 and 2014-15. Thus, they coincide with those for A-H share prices. Similarly, the IVX predictive regressions, presented in Figure 6 , suggest that A-ADR price differentials contain valuable information for predicting A-share price movements during these periods.

\subsection{Alternative Sources of AH Premia}

Several studies have attempted to explain the AH premium puzzle by looking at market and firm-specific factors which, under segmented markets, can cause price valuations of the same asset to differ across geographical locations (Wang and Jiang, 2004; Cai et al., 2011; Seasholes and Liu, 2011; Chung et al., 2013). In this section, we explore whether changes in such factors are linked to periods of exuberance in A-H price differentials. For doing so, we employ a dynamic panel probit (DPP).

Let $b_{i, t}$ denote a binary bubble indicator, which takes the value of unity when the BSADF statistic for firm $i$ exceeds its critical value at time $t$, and zero otherwise. The DPP model can be defined in reference to a theoretical relationship of the form

$$
b_{i, t}^{\star}=X_{i, t}^{\prime} \beta+\epsilon_{i, t}
$$

where $b_{i, t}^{\star}$ is an unobservable variable that determines the occurrence of a bubble in the share price of firm $i$ at time $t, X_{i, t}$ is a vector of covariates that includes a constant, the lag value of $b_{i, t}$, and market and firmspecific variables, $\beta$ is a coefficient vector, and $\epsilon_{i, t}$ is a normally distributed error term. The binary bubble indicator $b_{i, t}$ is related to the latent variable $b_{i, t}^{\star}$ according to

$$
b_{i, t}= \begin{cases}1, & \text { if } b_{i, t}^{\star}>0 \\ 0, & \text { otherwise }\end{cases}
$$

and the corresponding DPP model is given by

$$
\operatorname{Pr}\left(b_{i, t}=1 \mid X_{i, t}\right)=\Phi\left(X_{i, t}^{\prime} \beta\right)
$$

where $\Phi(\cdot)$ denotes the cumulative Gaussian distribution function. This model can be estimated via partial maximum likelihood, and the corresponding pooled probit estimator is consistent and asymptotically normal (Wooldridge, 2001, Ch. 13).

In line with previous literature, we consider the following potential sources of $\mathrm{AH}$ premia:

- Differences in Risk Appetite. The differential risk hypothesis postulates that A shares may sell at a premium because investors in mainland China are less risk averse in comparison to overseas investors and therefore demand a lower compensation for bearing risk (Ma, 1996). We proxy differences in risk appetite (risk) by the ratio of variances of A- and H-share returns (Wang and Jiang, 2004; Chung et 
al. 2013). Similarly to Wang and Jiang (2004), we measure the variance of returns using the squared residuals of a regression of returns on their one-period lagged values and local market index returns.

- Differences in Liquidity. According to the liquidity hypothesis, investor require compensation in the form of lower prices for purchasing assets which are relatively less liquid and have higher transaction costs (Amihud and Mendelson, 1986). We employ two proxies to capture differences in liquidity between markets. The first is given by the ratio of trading volumes (volume). The second is a transaction cost-based liquidity measure, defined as the difference between the bid-ask spreads of $\mathrm{A}$ and $\mathrm{H}$ shares (spread).

- Changes in Exchange Rate Expectations. Because firms incorporated in mainland China pay dividends in RMB, an expected depreciation of the Chinese currency implies a reduction in the expected future payoffs received by overseas investors from holding $\mathrm{H}$ shares. By altering the present value of $\mathrm{H}$ shares, movements in exchange rate expectations can cause $\mathrm{A}-$ and $\mathrm{H}$-share prices to diverge. A natural way to capture this effect is to include changes in ( $\log$ ) forward exchange rates (forward) in the DPP model. Unfortunately, forward exchange rates are only available for the period beginning in June 2009, which does not cover the first bubble episode in Chinese stock markets. To deal with this shortcoming, we use spot exchange rate returns (spot) in our main analysis. The results for forward rates, which are reported in Appendix A.3, are qualitatively similar.

- Differences in Aggregate Market Conditions. Previous studies show that aggregate market conditions are correlated with AH premia (Ma, 1996; Wang and Jiang, 2004; Chung et al., 2013). The findings of these studies suggest that when mainland Chinese stock markets are more bullish than the Hong Kong market, A-H price differentials tend to widen and vice versa. Though typically this behaviour is attributed to investor sentiment (see, e.g., Stambaugh et al., 2012, and the references therein) it is also consistent with the presence of a market-wide rational bubble that drives the prices of individual Chinese securities (as suggested by the IVX and BSADF results). Irrespective of whether the mechanism generating security prices involves rational bubbles or sentimental investors, differences in aggregate market conditions constitute a speculative source of $\mathrm{AH}$ premia and, in this aspect, differ from the factors outlined above which fall in the category of market fundamentals.$^{8}$ To proxy for relative market conditions, we follow Chung et al. (2013) and use the logarithm of the A-share price index over the H-share price index (market).

The above set of covariates does not account for two potential determinants of AH premia: macroeconomic conditions and asymmetric information. The reason for not examining the former is twofold. First,

\footnotetext{
${ }^{8}$ It should be noted that behavioural models establish a link between bubbles, transaction volume, and volatility Scheinkman and Xiong, 2003, Scheinkman 2014), which makes the distinction between fundamental and non-fundamental factors even less clear.
} 
because macroeconomic variables are observed at a low frequency (monthly or quarterly), their use requires temporal aggregation of the high-frequency financial variables and, most importantly, of the bubble indicator process $b_{i, t}$. This change in frequency can induce non-random measurement error in the left hand side variable of the probit model (especially given that the identified episodes of exuberance are relatively short) and thereby result in biased and inconsistent regression estimates (Hausman, 2001). Second, as shown by previous literature, macroeconomic variables do not appear to have a statistically significant relationship with

movements in AH premia so that their omission should not have a substantial impact on our results (Chung et al. 2013). With regard to information asymmetries between local and overseas investors, a proxy for this factor is given by market capitalization. However, market capitalization is itself a function of share prices and, as such, is directly influenced by the presence of speculative bubbles. Consequently, this proxy cannot shed light on whether episodes of exuberance in $\mathrm{A}-\mathrm{H}$ price differentials are due to asymmetric information or speculation.

\section{INSERT TABLE 6}

Having specified the set of explanatory variables, we turn to the DPP estimation results. Table 6 presents coefficient estimates, marginal effects, standard errors, likelihood ratio (LR) statistics, and McFadden $R^{2}$ s for two specifications, DPP1 and DPP2. In DPP1, the set of covariates is restricted to an intercept, the lagged value of the bubble indicator, and the measure of relative market conditions, i.e., $X_{i, t}=\left(1, b_{i, t-1}\right.$, market $)$. While, in DPP2, we also include the four variables that account for fundamental sources, i.e., $X_{i, t}=\left(1, b_{i, t-1}\right.$, market, risk, volume, spread, spot). Overall, the estimation results for the two DPP models suggest that fundamental sources cannot explain episodes of exuberance in A-H price differentials. The coefficients on risk, volume, spread and spot are individually statistically insignificant, and the LR test fails to reject the joint null hypothesis that all four coefficients are equal to zero with a $p$-value of 0.451 . Furthermore, the difference between the McFadden $R^{2} \mathrm{~s}$ of the restricted and unrestricted models is minimal. On the other hand, the coefficient on the market variable, which proxies for differences in market-wide speculation, is statistically significant and positive. This implies that as mainland Chinese markets become more bullish in comparison to the Hong-Kong market, there is a higher probability of an episode of exuberance in A-H price differentials occurring. According to the marginal effect estimates for DPP1 and DPP2 the magnitude of this relationship is substantial, with a one percent increase in the log difference between the A- and $\mathrm{H}$-share price indices being associated with an eleven percentage points increase in the probability of exuberance. In summary, the above result reinforce the view that speculative bubbles are present in the Chinese stock market. 


\section{Conclusion}

In the presence of capital controls, speculative bubbles can cause financial assets with the same market fundamentals to trade at different prices in different locations. These deviations from the law of one price display, like the bubble process, explosive dynamics and have predictive content for equity price movements. Based on these two predictions, we proposed a new approach for bubble detection in segmented markets that utilizes recursive unit root tests and predictive regressions. By applying these methods to data on Chinese cross-listed shares, we found strong evidence in favour of speculative dynamics. Interestingly, for the vast majority of cross-listed securities, the identified periods of exuberance coincide with the Chinese stock market frenzy of 2007 and the market crash of 2014-15. These findings point to a market-wide speculative factor driving Chinese share prices. 


\section{A Appendix}

The Appendix describes the econometric methods employed to test for speculative bubbles, and provides technical details for their estimation. Specifically, it outlines the GSADF test of Phillips et al. (2015a b), the proposed extension to a panel setting of Pavlidis et al. (2016), and the IVX method of Phillips and Magdalinos (2009) and Kostakis et al. (2015). The last section of the Appendix presents estimation results for the dynamic panel probit that includes changes in forward exchange rates.

\section{A.1 Recursive Unit Root Tests}

The GSADF Test Consider the following augmented Dickey-Fuller regression equation

$$
\Delta y_{t}=a_{r_{1}, r_{2}}+\gamma_{r 1, r 2} y_{t-1}+\sum_{j=1}^{k} \psi_{r_{1}, r_{2}}^{j} \Delta y_{t-j}+\epsilon_{t}
$$

where $y_{t}$ denotes a time series process, $\epsilon_{t} \stackrel{\text { iid }}{\sim} N\left(0, \sigma_{r_{1}, r_{2}}^{2}\right)$, and $r_{1}$ and $r_{2}$ denote fractions of the total sample size that specify the starting and ending points of a subsample period. We are interested in testing the null hypothesis of a unit root, $H_{0}: \gamma_{r_{1}, r_{2}}=0$, against the alternative of explosive behaviour in $y_{t}$, $H_{1}: \gamma_{r_{1}, r_{2}}>0$. Let

$$
\mathrm{ADF}_{r_{1}}^{r_{2}}=\widehat{\gamma}_{r 1, r 2} / \text { s.e. }\left(\widehat{\gamma}_{r 1, r 2}\right)
$$

denote the test statistic corresponding to this null hypothesis. Phillips et al. (2015a) propose a recursiverolling testing procedure which consists of estimating the ADF regression (20) on a large number of subsamples of the available data. The authors show that, under the null, the supremum of the resulting ADF statistics

$$
\operatorname{GSADF}\left(r_{0}\right)=\sup _{r_{2} \in\left[r_{0}, 1\right], r_{1} \in\left[0, r_{2}-r_{0}\right]} \operatorname{ADF}_{r_{1}}^{r_{2}}
$$

has the following limit distribution

$$
\sup _{r_{2} \in\left[r_{0}, 1\right], r_{1} \in\left[0, r_{2}-r_{0}\right]}\left\{\frac{\frac{1 / 2}{r}{ }_{w}\left[W\left(r_{2}\right)^{2}-W\left(r_{1}\right)^{2}-r_{w}\right]-\int_{r_{1}}^{r_{2}} W(r) d r\left[W\left(r_{2}\right)-W\left(r_{1}\right)\right]}{r_{w}^{1 / 2}\left\{r_{w} \int_{r_{1}}^{r_{2}} W(r)^{2} d r-\left[\int_{r_{1}}^{r_{2}} W(r) d r\right]^{2}\right\}^{1 / 2}}\right\} .
$$

where $r_{0}$ denotes the minimum window size, $r_{w}=r_{2}-r_{1}$, and $W$ is the standard brownian motion.

If the GSADF test rejects the null hypothesis of a unit root then, in a second stage, the exact period(s) during which the series under examination displayed explosive dynamics can be identified. The dating 
strategy of Phillips et al. (2015a b) is based on the BSADF statistic given by

$$
\operatorname{BSADF}_{r_{2}}\left(r_{0}\right)=\sup _{r_{1} \in\left[0, r_{2}-r_{0}\right]} \mathrm{ADF}_{r_{1}}^{r_{2}}
$$

The origination date of the bubble corresponds to the first observation that the BSADF statistic exceeds its critical value

$$
\widehat{r}_{e}=\inf _{r_{2} \in\left[r_{0}, 1\right]}\left\{r_{2}: \mathrm{BSADF}_{r_{2}}\left(r_{0}\right)>s c u_{r_{2}}^{\beta_{T}}\right\}
$$

and the termination date to the first observation after which the BSADF falls below its critical value

$$
\widehat{r}_{f}=\inf _{r_{2} \in\left[r_{0}, 1\right]}\left\{r_{2}: \operatorname{BSADF}_{r_{2}}\left(r_{0}\right)<s c u_{r_{2}}^{\beta_{T}}\right\}
$$

where $s c u_{r_{2}}^{\beta_{T}}$ is the $1-\beta_{T}$ critical value of the supremum ADF test based on $\left\lfloor r_{2} T\right\rfloor$ observations, and $\beta_{T}$ is the chosen significance level.

The computation of the BSADF and GSADF test statistics requires the selection of the minimum window size $r_{0}$ and the lag length $k$. Following Phillips et al. (2015a), we use the rule-of-thumb $r_{0}=$ $0.01+1.8 / \sqrt{T}$, and select a short lag length, $k=1$. The implementation of the unit root tests also necessitates the limit distributions of the BSADF and GSADF test statistics, which are non-standard. To obtain finite-sample critical values, we simulate 2000 random walk processes with $N(0,1)$ errors.

The Panel GSADF Test Inspired by the work of Im et al. (2003), Pavlidis et al. (2016) propose an extension of the GSADF test procedure to heterogeneous panels. Consider the multivariate version of the ADF regression equation

$$
\Delta y_{i, t}=a_{i, r_{1}, r_{2}}+\gamma_{i, r_{1}, r_{2}} y_{i, t-1}+\sum_{j=1}^{k} \psi_{i, r_{1}, r_{2}}^{j} \Delta y_{i, t-j}+\epsilon_{i, t}
$$

where $i=1, \ldots, N$, denotes the cross-listed company index. The null hypothesis of the panel test is that all $N$ cross-listed companies have a unit root, $H_{0}: \gamma_{i, r_{1}, r_{2}}=0$, against the alternative of explosive behaviour in a subset of units, $H_{1}: \gamma_{i, r_{1}, r_{2}}>0$ for some $i$. This alternative allows for $\gamma_{i, r_{1}, r_{2}}$ to differ across units and, therefore, is more general than approaches based on the homogeneous alternative hypothesis.

The panel procedure of Pavlidis et al. (2016) is based on the average of the individual BSADF statistics at each time period

$$
\text { panel } \mathrm{BSADF}_{r_{2}}\left(r_{0}\right)=\frac{1}{N} \sum_{i=1}^{N} \operatorname{BSADF}_{i, r_{2}}\left(r_{0}\right),
$$

which provides a measure of overall exuberance in the sample. Given 23 , the definition of the panel 
GSADF is simply

$$
\text { panel GSADF }\left(r_{0}\right)=\sup _{r_{2} \in\left[r_{0}, 1\right]} \text { panel } \operatorname{BSADF}_{r_{2}}\left(r_{0}\right) .
$$

The results of Maddala and Wu (1999) and Chang (2004) show that the distribution of panel unit root tests based on mean statistics is not invariant to cross-sectional dependence of the error terms $\epsilon_{i}$. To deal with this complication, Pavlidis et al. (2016) employ a sieve bootstrap procedure to draw statistical inference. The procedure consists of the following steps:

1. For each panel unit $i$, impose the null hypothesis and fit the restricted ADF regression,

$$
\Delta y_{i, t}=a_{i, r_{1}, r_{2}}+\sum_{j=1}^{k} \psi_{i, r_{1}, r_{2}}^{j} \Delta y_{i, t-j}+\epsilon_{i, t}
$$

to obtain $\hat{a}_{i, r_{1}, r_{2}}, \psi_{i, r_{1}, r_{2}}^{j}$ for $j=1, \ldots, k$, and $\hat{\epsilon}_{i}$.

2. To preserve the dependence structure of the error term, generate bootstrap residuals, $\epsilon_{i, t}^{b}$, by sampling with replacement columns from the residual matrix $\hat{\epsilon}$.

3. Recursively simulate artificial samples for first differences,

$$
\Delta y_{i, t}^{b}=a_{i, r_{1}, r_{2}}+\sum_{j=1}^{k} \psi_{i, r_{1}, r_{2}}^{j} \Delta y_{i, t-j}^{b}+\epsilon_{i, t}^{b},
$$

and for levels,

$$
\Delta y_{i, t}^{b}=\sum_{p=1}^{t} \Delta y_{i, p}^{b}
$$

4. Compute the sequence of panel BSADF statistics and the panel GSADF statistic for the simulated series.

5. Repeat steps 2 to 4 one thousand times to obtain the empirical distribution of the test statistics under the null.

Similarly to the univariate testing procedure, dating episodes of overall exuberance consists of comparing the panel BSADF with the sequence of critical values obtained from the bootstrap procedure. The origination date is set equal to the first observation that the panel BSADF statistic exceeds the $1-\beta_{T}$ critical value, and the termination date is set equal to the first observation that the Panel BSADF falls below the $1-\beta_{T}$ critical value. 


\section{A.2 The IVX Testing Procedure}

Consider the following bivariate system

$$
\begin{aligned}
& y_{t+1}=\alpha x_{t}+u_{1, t+1}, \\
& x_{t+1}=\rho x_{t}+u_{2, t+1},
\end{aligned}
$$

where the errors $\left(u_{1, t+1}, u_{2, t+1}\right)^{\prime}$ follow a martingale difference sequence, and $\rho=1+c / T^{\gamma}$ for some $\gamma \geq 0$. In this setting, the AR coefficient for the regressor is allowed to take a wide range of values. Depending on the value of $c$ and $\gamma$, the regressor can be an i) integrated ( $c=0$ or $\gamma>1)$, ii) local-to-unity ( $c \neq 0$ and $\gamma=1)$, iii) near stationary ( $c<0$ and $\gamma \in(0,1)$ ), iv) locally explosive ( $c>0$ and $\gamma=1)$, or v) mildly explosive $(c>0$ and $\gamma \in(0,1))$ process. The IVX procedure is based on the creation of an instrument $z_{t}$ which, although relies on the regressor, always falls in the near stationary category iii. In particular, given an artificial autoregressive scalar,

$$
\rho_{z}=1+c_{z} / T^{\zeta}, \quad \zeta \in(0,1), \quad c_{z}<0,
$$

the IVX instrument is initialized at zero and sequentially computed for the remaining periods according to

$$
z_{t}=\rho_{z} z_{t-1}+\Delta x_{t}
$$

It can be shown that the estimator

$$
\hat{\alpha}_{\mathrm{IVX}}=\frac{\sum z_{t} y_{t+1}}{\sum z_{t} x_{t}}
$$

has the following limit theory

$$
T^{\frac{1+\zeta}{2}}\left(\hat{\alpha}_{\mathrm{IVX}}-\alpha\right) \Longrightarrow \psi^{\prime}
$$

where $\psi^{\prime}$ is a mixed normal variable, and the IVX test statistic

$$
\operatorname{IVX}=\frac{\hat{\alpha}_{\text {IVX }}-\alpha}{\hat{\sigma}_{\text {IVX }}}
$$

is standard normal (Phillips and Magdalinos, 2009; Kostakis et al., 2015; Phillips and Lee, 2013). Simulation results in Kostakis et al. (2015) and Pavlidis et al. (2017) indicate that the IVX test has good size and power properties in finite samples.

\section{A.3 Dynamic Panel Probit Results for Forward Exchange Rates}

INSERT TABLE7 


\section{References}

Amihud, Yakov, and Haim Mendelson (1986) 'Asset pricing and the bid-ask spread.' Journal of Financial Economics 17(2), 223-249

Blanchard, Olivier J. (1979) 'Speculative bubbles, crashes and rational expectations.' Economics Letters 3(4), 387-389

Cai, Charlie X, Paul B McGuinness, and Qi Zhang (2011) 'The pricing dynamics of cross-listed securities: The case of Chinese A-and H-shares.' Journal of Banking \& Finance 35(8), 2123-2136

Campbell, John Y., and Motohiro Yogo (2006) 'Efficient tests of stock return predictability.' Journal of Financial Economics 81(1), 27-60

Carpenter, Jennifer N, and Robert F Whitelaw (2017) 'The development of China's stock market and stakes for the global economy.' Annual Review of Financial Economics 9, 233-257

Chan, Kalok, Albert J Menkveld, and Zhishu Yang (2008) 'Information asymmetry and asset prices: Evidence from the China foreign share discount.' The Journal of Finance 63(1), 159-196

Chang, Yoosoon (2004) 'Bootstrap unit root tests in panels with cross-sectional dependency.' Journal of econometrics 120(2), 263-293

Chen, Kaiji, and Yi Wen (2017) 'The great housing boom of China.' American Economic Journal: Macroeconomics $9(2), 73-114$

Chen, Zhiwu, and Peter J. Knez (1995) 'Measurement of market integration and arbitrage.' The Review of Financial Studies 8(2), 287-325

Chung, Tsz-Kin, Cho-Hoi Hui, and Ka-Fai Li (2013) 'Explaining share price disparity with parameter uncertainty: Evidence from Chinese A-and H-shares.' Journal of Banking \& Finance 37(3), 1073-1083

Diba, Behzad T., and Herschel I. Grossman (1988) 'The theory of rational bubbles in stock prices.' Economic Journal 98(392), 746-54

Elliott, Graham, Ulrich K. Müller, and Mark W. Watson (2015) 'Nearly optimal tests when a nuisance parameter is present under the null hypothesis.' Econometrica 83(2), 771-811

Evans, George W. (1991) 'Pitfalls in testing for explosive bubbles in asset prices.' American Economic Review 81(4), 922-930 
Fang, Hanming, Quanlin Gu, Wei Xiong, and Li-An Zhou (2016) 'Demystifying the Chinese housing boom.' NBER macroeconomics annual 30(1), 105-166

Feng, Lei, and Mark Seasholes (2003) 'A profile of individual investors in an emerging stock market.' Working Paper

Fernald, John, and John H. Rogers (2002) 'Puzzles in the Chinese stock market.' Review of Economics and Statistics 84(3), 416-432

Flood, Robert P., and Peter M. Garber (1994) Speculative bubbles, speculative attacks, and policy switching (MIT Press)

Froot, Kenneth A., and Emil M. Dabora (1999) 'How are stock prices affected by the location of trade?' Journal of Financial Economics 53(2), 189 - 216

Gan, Li, Zhichao Yin, Nan Jia, Shu Xu, Shuang Ma, and Lu Zheng (2014) Data you need to know about China (Springer)

Glaeser, Edward, Wei Huang, Yueran Ma, and Andrei Shleifer (2017) 'A real estate boom with Chinese characteristics.' Journal of Economic Perspectives 31(1), 93-116

Gürkaynak, Refet S. (2008) 'Econometric tests of asset price bubbles: Taking stock.' Journal of Economic Surveys 22(1), 166-186

Hamilton, James D., and Charles H. Whiteman (1985) 'The observable implications of self-fulfilling expectations.' Journal of Monetary Economics 16(3), 353-373

Hausman, Jerry (2001) 'Mismeasured variables in econometric analysis: Problems from the right and problems from the left.' The Journal of Economic Perspectives 15(4), 57-67

Homm, Ulrich, and Jörg Breitung (2012) 'Testing for speculative bubbles in stock markets: A comparison of alternative methods.' Journal of Financial Econometrics 10(1), 198-231

Im, Kyung So, M Hashem Pesaran, and Yongcheol Shin (2003) 'Testing for unit roots in heterogeneous panels.' Journal of econometrics 115(1), 53-74

Jansson, Michael, and Marcelo J. Moreira (2006) 'Optimal inference in regression models with nearly integrated regressors.' Econometrica 74(3), 681-714

Jia, Chunxin, Yaping Wang, and Wei Xiong (2017) 'Market segmentation and differential reactions of local and foreign investors to analyst recommendations.' The Review of Financial Studies 30(9), 2972-3008 
Kilian, Lutz (1999) 'Exchange rates and monetary fundamentals: What do we learn from long-horizon regressions?' Journal of Applied Econometrics 14(5), 491-510

Kilian, Lutz, and Mark P. Taylor (2003) 'Why is it so difficult to beat the random walk forecast of exchange rates?' Journal of International Economics 60(1), 85-107

Kostakis, Alexandros, Tassos Magdalinos, and Michalis P. Stamatogiannis (2015) 'Robust econometric inference for stock return predictability.' Review of Financial Studies 28(5), 1506-1553

Lamont, Owen A., and Richard H. Thaler (2003) 'Anomalies: The law of one price in financial markets.' Journal of Economic Perspectives 17(4), 191-202

Liu, Yu-Jane, Zheng Zhang, and Longkai Zhao (2014) 'Speculation spillovers.' Management Science 61(3), 649-664

Ma, Xianghai (1996) 'Capital controls, market segmentation and stock prices: Evidence from the Chinese stock market.' Pacific-Basin Finance Journal 4(2-3), 219-239

Maddala, Gangadharrao S, and Shaowen Wu (1999) 'A comparative study of unit root tests with panel data and a new simple test.' Oxford Bulletin of Economics and statistics 61(S1), 631-652

Mao, Guangyu, and Yan Shen (2019) 'Bubbles or fundamentals? Modeling provincial house prices in China allowing for cross-sectional dependence.' China Economic Review 53, 53-64

Mei, Jianping, Jose Scheinkman, and Wei Xiong (2005) 'Speculative trading and stock prices: Evidence from Chinese AB share premia.' Technical Report, National Bureau of Economic Research

Nielsen, Bent (2010) 'Analysis of coexplosive processes.' Econometric Theory 26(3), 882-915

Pavlidis, Efthymios G., Alisa Yusupova, Ivan Paya, David A. Peel, Enrique Martínez-García, Adrienne Mack, and Valerie Grossman (2016) 'Episodes of exuberance in housing markets: In search of the smoking gun.' The Journal of Real Estate Finance and Economics 53(4), 419-449

Pavlidis, Efthymios G., Enrique Martinez-Garcia, and Valerie Grossman (2019) 'Detecting periods of exuberance: A look at the role of aggregation with an application to house prices.' Economic Modelling $80,87-102$

Pavlidis, Efthymios G., Ivan Paya, and David A. Peel (2017) 'Testing for speculative bubbles using spot and forward prices.' International Economic Review 58(4), 1191-1226

Pavlidis, Efthymios G., Ivan Paya, and David A. Peel (2018) 'Using market expectations to test for speculative bubbles in the crude oil market.' Journal of Money, Credit and Banking 50(5), 833-856 
Phillips, Peter C. B. (2014) 'On confidence intervals for autoregressive roots and predictive regression.' Econometrica 82(3), 1177-1195

Phillips, Peter C. B., and Ji Hyung Lee (2013) 'Predictive regression under various degrees of persistence and robust long-horizon regression.' Journal of Econometrics 177(2), 250-264

Phillips, Peter C. B., and Tassos Magdalinos (2009) 'Econometric inference in the vicinity of unity.' CoFie Working Paper 7, Singapore Management University

Phillips, Peter C. B., Shuping Shi, and Jun Yu (2015a) 'Testing for multiple bubbles: Historical episodes of exuberance and collapse in the S\&P 500.' International Economic Review 56(4), 1043-1078

_ (2015b) 'Testing for multiple bubbles: Limit theory of real-time detectors.' International Economic Review 56, 1079-1134

Scheinkman, Jos A., and Wei Xiong (2003) 'Overconfidence and speculative bubbles.' Journal of Political Economy 111(6), 1183-1220

Scheinkman, Jose A. (2014) Speculation, trading, and bubbles (Columbia University Press)

Seasholes, Mark S., and Clark Liu (2011) 'Trading imbalances and the law of one price.' Economics Letters 112(1), 132-134

Stambaugh, Robert F., Jianfeng Yu, and Yu Yuan (2012) 'The short of it: Investor sentiment and anomalies.' Journal of Financial Economics 104(2), 288-302

Wang, Steven Shuye, and Li Jiang (2004) 'Location of trade, ownership restrictions, and market illiquidity: Examining Chinese A-and H-shares.' Journal of Banking \& Finance 28(6), 1273-1297

Wooldridge, Jeffrey M. (2001) Econometric analysis of cross section and panel data, vol. 1 of MIT Press Books (The MIT Press)

Wu, Jing, Joseph Gyourko, and Yongheng Deng (2015) 'Real estate collateral value and investment: The case of China.' Journal of urban Economics 86, 43-53

Xiong, Wei, and Jialin Yu (2011) 'The Chinese warrants bubble.' American Economic Review 101(6), 272353

Zhi, Tianhao, Zhongfei Li, Zhiqiang Jiang, Lijian Wei, and Didier Sornette (2019) 'Is there a housing bubble in China?' Emerging Markets Review 39, 120-132 


\section{Tables \& Figures}

\section{TABLE 1 - DISTRIBUTION OF CASH MARKET TRADING VOLUME BY INVESTOR TYPE AND ORIGIN}

\begin{tabular}{|c|c|c|c|c|c|c|c|c|c|c|}
\hline & 2006-07 & $2007-08$ & 2008-09 & $2009-10$ & $2010-11$ & $2011-12$ & $2012-13$ & 2013-14 & 2014-15 & Full Sample \\
\hline Retail Total & $32 \%$ & $29 \%$ & $29 \%$ & $25 \%$ & $26 \%$ & $21 \%$ & $23 \%$ & $25 \%$ & $27 \%$ & $26 \%$ \\
\hline - Local Retail & $28 \%$ & $26 \%$ & $25 \%$ & $21 \%$ & $22 \%$ & $17 \%$ & $18 \%$ & $20 \%$ & $19 \%$ & $22 \%$ \\
\hline - Overseas Retail & $4 \%$ & $3 \%$ & $4 \%$ & $4 \%$ & $4 \%$ & $4 \%$ & $5 \%$ & $5 \%$ & $8 \%$ & $5 \%$ \\
\hline Institutional Total & $64 \%$ & $65 \%$ & $62 \%$ & $65 \%$ & $62 \%$ & $63 \%$ & $61 \%$ & $58 \%$ & $50 \%$ & $61 \%$ \\
\hline - Local Institutional & $25 \%$ & $27 \%$ & $24 \%$ & $23 \%$ & $20 \%$ & $21 \%$ & $20 \%$ & $24 \%$ & $19 \%$ & $23 \%$ \\
\hline - Overseas Institutional & $39 \%$ & $38 \%$ & $38 \%$ & $42 \%$ & $42 \%$ & $42 \%$ & $41 \%$ & $34 \%$ & $31 \%$ & $39 \%$ \\
\hline Other & $4 \%$ & $6 \%$ & $8 \%$ & $10 \%$ & $12 \%$ & $15 \%$ & $16 \%$ & $16 \%$ & $22 \%$ & $12 \%$ \\
\hline US+Europe & $71 \%$ & $74 \%$ & $70 \%$ & $69 \%$ & $69 \%$ & $69 \%$ & $67 \%$ & $64 \%$ & $56 \%$ & $68 \%$ \\
\hline Asia & $22 \%$ & $22 \%$ & $26 \%$ & $27 \%$ & $22 \%$ & $21 \%$ & $24 \%$ & $29 \%$ & $36 \%$ & $25 \%$ \\
\hline
\end{tabular}

Source: Hong Kong Exchanges and Clearing Limited Cash Market Transaction Surveys from 2007 to 2016.

TABle 2 - Chinese CROSS-LISTED COMPANIES

\begin{tabular}{|c|c|c|c|c|c|}
\hline Company Name & Abbreviation & Sector & A-Ticker & H-Ticker & ADR-Ticker \\
\hline Angang Steel & Angang & Materials & 000898.SZ & 0347.HK & \\
\hline Anhui Conch Cement & Anhui Conch & Materials & 600585.SS & 0914.HK & \\
\hline Anhui Expressway & Anhui Express & Industrials & 600012.SS & 0995.HK & \\
\hline Guangzhou Baiyunshan Pharmaceutical Holdings & Baiyunshan & Health Care & 600332.SS & 0874.HK & \\
\hline China Eastern Airlines & China East Air & Industrials & 600115.SS & 0670.HK & CEA \\
\hline China Petroleum \& Chemical & China Petroleu & Energy & 600028.SS & 0386.HK & SNP \\
\hline COSCO Shipping Energy Transportation & Cosco Shipping & Industrials & 600026.SS & 1138.HK & \\
\hline CSSC Offshore \& Marine Engineering Group & CSSC Marine En & Industrials & 600685.SS & 0317.HK & \\
\hline Dongfang Electric & Dongfang Elec & Industrials & 600875.SS & 1072.HK & \\
\hline Huadian Power International & Huadian Power & Utilities & 600027.SS & 1071.HK & \\
\hline Huaneng Power International Inc & Huaneng Power & Utilities & 600011.SS & 0902.HK & HNP \\
\hline Jiangsu Expressway & Jiangsu Exp & Industrials & 600377.SS & 0177.HK & \\
\hline Jiangxi Copper & Jiangxi Copper & Materials & 600362.SS & 0358.HK & \\
\hline Beijing Jingcheng Machinery Electric & Jingcheng Mach & Industrials & 600860.SS & 0187.HK & \\
\hline Shenji Group Kunming Machine Tool & Kunming Machin & Industrials & 600806.SS & 0300.HK & \\
\hline Maanshan Iron \& Steel & Maanshan Iron & Materials & 600808.SS & 0323.HK & \\
\hline Nanjing Panda Electronics & Nanjing Panda & Information Technology & 600775.SS & 0553.HK & \\
\hline Northeast Electric Development & Northeast Elec & Industrials & 000585.SZ & 0042.HK & \\
\hline Sinopec Shanghai Petrochemical & S Sh Pechem & Materials & 600688.SS & 0338.HK & SHI \\
\hline Sinopec Oilfield Service & Sinopec Oilfie & Energy & 600871.SS & 1033.HK & \\
\hline China Southern Airlines & Southern Air & Industrials & 600029.SS & 1055.HK & $\mathrm{ZNH}$ \\
\hline Shenzhen Expressway & Sz Expressway & Industrials & 600548.SS & 0548.HK & \\
\hline Tianjin Capital Environmental Protection Group & Tianjin Cap & Industrials & 600874.SS & 1065.HK & \\
\hline Tsingtao Brewery & Tsingtao Brew & Consumer Staples & 600600.SS & 0168.HK & \\
\hline Shandong Xinhua Pharmaceutical & Xinhua Pharm & Health Care & 000756.SZ & 0719.HK & \\
\hline Yanzhou Coal Mining & Yanzhou Coal & Energy & 600188.SS & 1171.HK & \\
\hline ZTE & ZTE & Information Technology & 000063.SZ & 0763.HK & \\
\hline
\end{tabular}

Notes: SS, SZ, and HK indicate shares listed on the Shanghai Stock Exchange, the Shenzhen Stock Exchange, and the Stock Exchange of Hong Kong, respectively. All American Depository Receipts (ADRs) are traded on the New York Stock Exchange. 
TABle 3 - DesCRIPTIVE STATISTICS OF A- TO H-SHARE PRICE RATIOS

\begin{tabular}{|c|c|c|c|c|c|}
\hline Company & Mean & $\mathrm{SD}$ & Min & Max & $\mathrm{AR}(1)$ \\
\hline Angang & 1.080 & 0.280 & 0.704 & 2.313 & 0.953 \\
\hline Anhui Conch & 0.929 & 0.145 & 0.603 & 1.491 & 0.930 \\
\hline Anhui Express & 1.449 & 0.475 & 0.863 & 3.184 & 0.989 \\
\hline Baiyunshan & 1.949 & 0.524 & 1.200 & 3.559 & 0.969 \\
\hline China East Air & 2.222 & 0.877 & 1.128 & 5.949 & 0.969 \\
\hline China Petroleu & 1.381 & 0.419 & 0.838 & 2.553 & 0.978 \\
\hline Cosco Shipping & 1.443 & 0.382 & 0.866 & 2.768 & 0.955 \\
\hline CSSC Marine En & 1.910 & 0.711 & 0.816 & 3.843 & 0.981 \\
\hline Dongfang Elec & 1.449 & 0.349 & 0.861 & 2.772 & 0.954 \\
\hline Huadian Power & 1.937 & 0.686 & 0.816 & 3.950 & 0.976 \\
\hline Huaneng Power & 1.380 & 0.345 & 0.787 & 2.184 & 0.968 \\
\hline Jiangsu Exp & 1.029 & 0.163 & 0.706 & 1.554 & 0.933 \\
\hline Jiangxi Copper & 1.874 & 0.505 & 1.047 & 3.589 & 0.957 \\
\hline Jingcheng Mach & 3.293 & 0.871 & 1.571 & 7.375 & 0.945 \\
\hline Kunming Machin & 2.792 & 0.717 & 0.905 & 5.505 & 0.959 \\
\hline Maanshan Iron & 1.444 & 0.473 & 0.838 & 3.530 & 0.962 \\
\hline Nanjing Panda & 3.684 & 1.043 & 1.673 & 6.180 & 0.972 \\
\hline Northeast Elec & 3.469 & 0.856 & 1.404 & 7.344 & 0.947 \\
\hline S Sh Pechem & 2.895 & 0.904 & 1.208 & 5.070 & 0.971 \\
\hline Sinopec Oilfie & 3.800 & 1.189 & 1.273 & 8.851 & 0.962 \\
\hline Southern Air & 1.933 & 0.681 & 1.008 & 4.258 & 0.973 \\
\hline Sz Expressway & 1.495 & 0.295 & 0.892 & 2.610 & 0.943 \\
\hline Tianjin Cap & 2.958 & 0.886 & 1.430 & 6.569 & 0.969 \\
\hline Tsingtao Brew & 1.110 & 0.207 & 0.808 & 1.824 & 0.951 \\
\hline Xinhua Pharm & 2.972 & 0.557 & 1.684 & 4.647 & 0.943 \\
\hline Yanzhou Coal & 1.837 & 0.605 & 0.870 & 3.591 & 0.966 \\
\hline ZTE & 1.205 & 0.238 & 0.825 & 2.316 & 0.936 \\
\hline
\end{tabular}

Note: The table presents means, standard deviations, minimum and maximum values, and AR(1) coefficient estimates for A-H price ratios. 
Table 4 - Bubble Detection Tests: A-H Shares

\begin{tabular}{lll|lll}
\hline Company & ADF & GSADF & Company & ADF & GSADF \\
\hline Angang & -3.304 & $3.197^{* * *}$ & Kunming Machin & -3.008 & 2.009 \\
Anhui Conch & -3.474 & 1.004 & Maanshan Iron & -3.003 & $3.386^{* * *}$ \\
Anhui Express & -1.140 & $7.012^{* * *}$ & Nanjing Panda & -4.339 & $4.233^{* * *}$ \\
Baiyunshan & -3.803 & 1.682 & Northeast Elec & -2.661 & $3.432^{* * *}$ \\
China East Air & -2.727 & $5.718^{* * *}$ & S Sh Pechem & -2.631 & $4.142^{* * *}$ \\
China Petroleu & -2.017 & $3.835^{* * *}$ & Sinopec Oilfie & -3.024 & $5.640^{* * *}$ \\
Cosco Shipping & -2.941 & $3.033^{* * *}$ & Southern Air & -2.705 & $4.230^{* * *}$ \\
CSSC Marine En & -2.850 & $4.722^{* * *}$ & Sz Expressway & -3.522 & $4.606^{* * *}$ \\
Dongfang Elec & -4.002 & $2.348^{* *}$ & Tianjin Cap & -3.818 & $4.099^{* * *}$ \\
Huadian Power & -3.000 & $3.078^{* * *}$ & Tsingtao Brew & -3.063 & $3.002^{* * *}$ \\
Huaneng Power & -2.583 & $4.018^{* * *}$ & Xinhua Pharm & -2.872 & $4.751^{* * *}$ \\
Jiangsu Exp & -3.175 & $2.519^{* *}$ & Yanzhou Coal & -3.660 & $3.802^{* * *}$ \\
Jiangxi Copper & -2.831 & $4.530^{* * *}$ & ZTE & -3.467 & 1.450 \\
Jingcheng Mach & -2.993 & $4.661^{* * *}$ & & Panel & $1.757^{* * *}$ \\
\hline AH Premium Index & -2.718 & $3.225^{* * *}$ & & & \\
\hline
\end{tabular}

Notes: The table reports ADF, GSADF, and panel GSADF test statistics for the AH premium index and the 27 cross-listed companies. ${ }^{*}, * *$ and ${ }^{* * *}$ denote statistical significance at the ten, five, and one percent levels, respectively. The minimum window size for the GSADF and panel GSADF test is set equal to 48 weeks. Finite sample critical values are obtained from using 2000 simulations.

Table 5 - Bubble Detection Tests: American Depository Receipts

\begin{tabular}{lccccc}
\hline & \multicolumn{3}{c}{ ADR-H } & & \multicolumn{2}{c}{ A-ADR } \\
\cline { 2 - 3 } \cline { 5 - 6 } Company & ADF & GSADF & & ADF & GSADF \\
\hline China East Air & -16.376 & -0.683 & & -2.737 & $5.597^{* * *}$ \\
China Petroleu & -16.267 & -3.114 & & -2.026 & $3.964^{* * *}$ \\
Huaneng Power & -14.811 & -0.770 & & -2.610 & $3.547^{* * *}$ \\
S Sh Pechem & -16.075 & -2.254 & & -2.614 & $3.966^{* * *}$ \\
Southern Air & -15.488 & -0.429 & & -2.698 & $4.068^{* * *}$ \\
\hline Panel & & -2.854 & & $2.342^{* * *}$ \\
\hline
\end{tabular}

Notes: The table reports GSADF test statistics for the difference between the prices of A shares and ADRs, as well as the difference between the prices of ADRs and $\mathrm{H}$ shares. ${ }^{*},{ }^{* *}$ and ${ }^{* * *}$ denote statistical significance at the ten, five, and one percent levels, respectively. The minimum window size for the GSADF and panel GSADF test is set equal to 48 weeks. Finite sample critical values are obtained from using 2000 simulations. 
TAble 6 - Estimation Results for the Dynamic Panel Probit model

\begin{tabular}{|c|c|c|c|c|}
\hline & \multicolumn{2}{|c|}{ DPP1 } & \multicolumn{2}{|c|}{$\mathrm{DPP} 2$} \\
\hline & Coefficient Estimate & Marginal Effect & Coefficient Estimate & Marginal Effect \\
\hline lagged exuberance & $\begin{array}{c}2.672^{* * *} \\
(0.067)\end{array}$ & $\begin{array}{c}0.628^{* * *} \\
(0.024)\end{array}$ & $\begin{array}{c}2.670^{* * *} \\
(0.068)\end{array}$ & $\begin{array}{c}0.626^{* * *} \\
(0.024)\end{array}$ \\
\hline market & $\begin{array}{c}3.014^{* * *} \\
(0.300)\end{array}$ & $\begin{array}{c}0.107^{* * *} \\
(0.010)\end{array}$ & $\begin{array}{c}3.043^{* * *} \\
(0.305)\end{array}$ & $\begin{array}{c}0.107^{* * *} \\
(0.010)\end{array}$ \\
\hline risk & & & $\begin{array}{l}-7.6 \mathrm{e}-08 \\
(5.3 \mathrm{e}-07)\end{array}$ & $\begin{array}{l}-2.7 \mathrm{e}-09 \\
(1.9 \mathrm{e}-08)\end{array}$ \\
\hline volume & & & $\begin{array}{c}0.003 \\
(0.002)\end{array}$ & $\begin{array}{c}1.1 \mathrm{e}-04 \\
(7.5 \mathrm{e}-05)\end{array}$ \\
\hline spread & & & $\begin{array}{l}-0.646 \\
(0.509)\end{array}$ & $\begin{array}{l}-0.023 \\
(0.018)\end{array}$ \\
\hline spot & & & $\begin{array}{c}7.004 \\
(10.048)\end{array}$ & $\begin{array}{c}0.247 \\
(0.355)\end{array}$ \\
\hline constant & $\begin{array}{c}-2.734^{* * *} \\
(0.065)\end{array}$ & & $\begin{array}{c}-2.745^{* * *} \\
(0.066)\end{array}$ & \\
\hline $\begin{array}{l}\text { McFadden } R^{2} \\
\text { LR Statistic ( } p \text {-value) }\end{array}$ & 0.526 & & $\begin{array}{c}0.527 \\
3.680(0.451)\end{array}$ & \\
\hline
\end{tabular}

Notes: The table presents coefficient estimates, marginal effects, standard errors, and McFadden $R^{2} \mathrm{~s}$ for a restricted (DPP1) and an unrestricted (DPP2) model specification. It also reports the likelihood ratio (LR) statistic and the corresponding $p$-value for the restriction that the coefficients on risk, liquidity, spread, and spot are equal to zero. ${ }^{* * *}$ and ${ }^{* * *}$ denote statistical significance at the ten, five, and one percent levels, respectively. 
TAble 7 - Estimation Results for the Dynamic Panel Probit model (Forward Rates)

\begin{tabular}{|c|c|c|c|c|}
\hline & \multicolumn{2}{|c|}{ DPP1 } & \multicolumn{2}{|c|}{ DPP2 } \\
\hline & Coefficient Estimate & Marginal Effect & Coefficient Estimate & Marginal Effect \\
\hline lagged exuberance & $\begin{array}{c}2.583^{* * *} \\
(0.090)\end{array}$ & $\begin{array}{c}0.583^{* * *} \\
(0.033)\end{array}$ & $\begin{array}{c}2.579^{* * *} \\
(0.090)\end{array}$ & $\begin{array}{c}0.581^{* * *} \\
(0.033)\end{array}$ \\
\hline market & $\begin{array}{c}3.526^{* * *} \\
(0.538)\end{array}$ & $\begin{array}{c}0.107^{* * *} \\
(0.015)\end{array}$ & $\begin{array}{c}3.513^{* * *} \\
(0.544)\end{array}$ & $\begin{array}{c}0.106^{* * *} \\
(0.015)\end{array}$ \\
\hline risk & & & $\begin{array}{l}-5.8 \mathrm{e}-08 \\
(4.5 \mathrm{e}-07)\end{array}$ & $\begin{array}{l}-1.7 \mathrm{e}-09 \\
(1.4 \mathrm{e}-08)\end{array}$ \\
\hline volume & & & $\begin{array}{c}0.003 \\
(0.002)\end{array}$ & $\begin{array}{c}1.0 \mathrm{e}-04 \\
(7.1 \mathrm{e}-05)\end{array}$ \\
\hline spread & & & $\begin{array}{l}-0.371 \\
(0.847)\end{array}$ & $\begin{array}{l}-0.011 \\
(0.026)\end{array}$ \\
\hline forward & & & $\begin{array}{l}11.687 \\
(9.038)\end{array}$ & $\begin{array}{c}0.353 \\
(0.274)\end{array}$ \\
\hline constant & $\begin{array}{c}-2.751^{* * *} \\
(0.089)\end{array}$ & & $\begin{array}{c}-2.760^{* * *} \\
(0.090)\end{array}$ & \\
\hline $\begin{array}{l}\text { McFadden } R^{2} \\
\text { LR Statistic ( } p \text {-value) }\end{array}$ & 0.446 & & $\begin{array}{c}0.448 \\
3.218(0.522)\end{array}$ & \\
\hline
\end{tabular}

Notes: The table presents coefficient estimates, marginal effects, standard errors, and McFadden $R^{2}$ s for a restricted (DPP1) and an unrestricted (DPP2) model specification. It also reports the likelihood ratio (LR) statistic and the corresponding $p$-value for the restriction that the coefficients on risk, liquidity, spread, and forward are equal to zero. ${ }^{*},{ }^{* *}$ and ${ }^{* * *}$ denote statistical significance at the ten, five, and one percent levels, respectively. 


\section{Figure 1 - Hang Seng AH Premium IndeX}

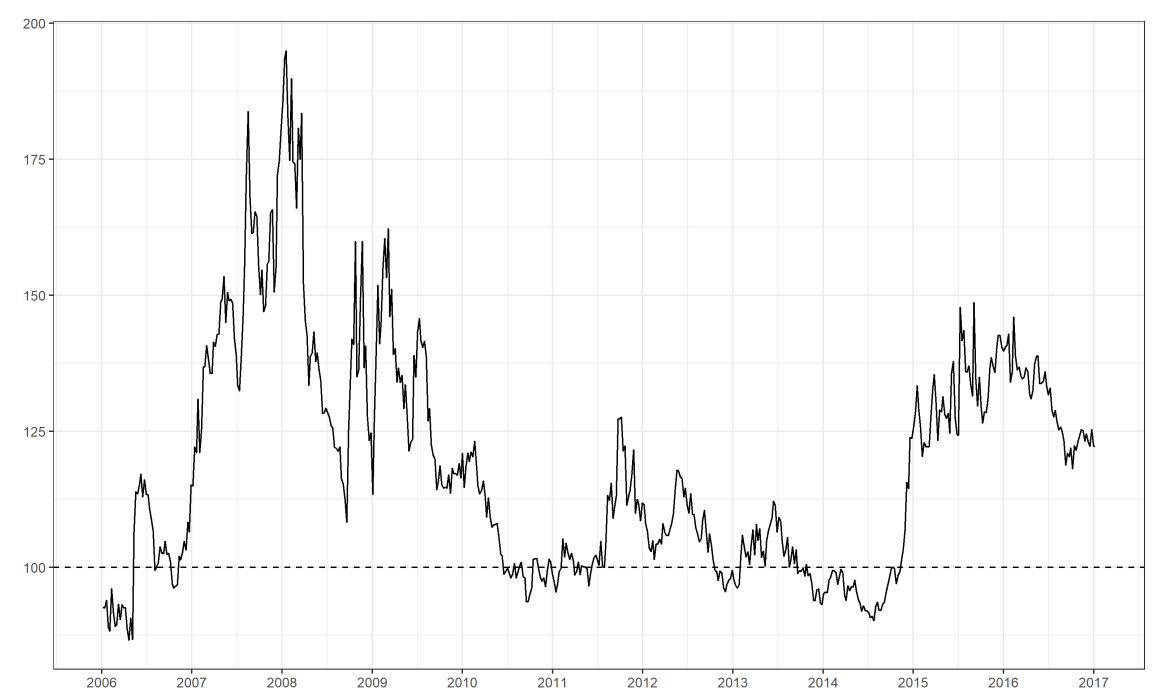

Figure 2 - Date-Stamping Periods of Market Exuberance

\section{AH PREMIUM INDEX}

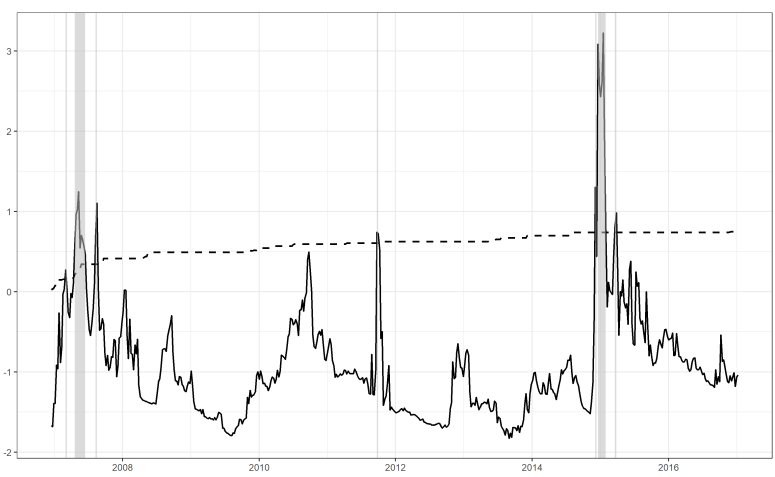

PANEL AH

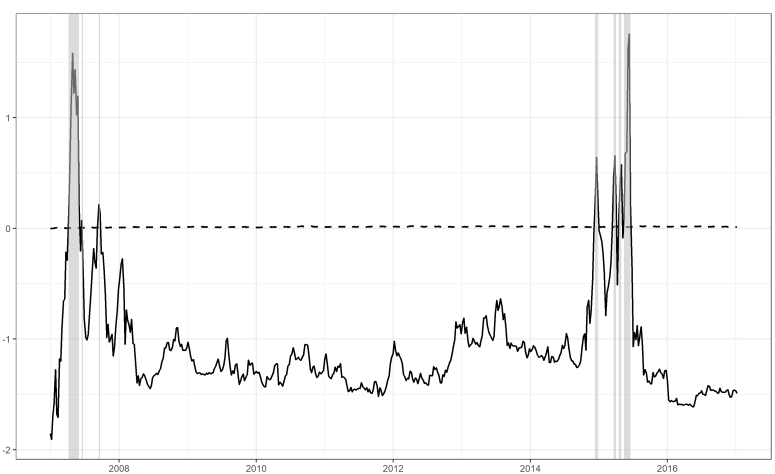

Notes: The plots display the sequence of BSADF statistics (solid line) together with the corresponding 95 percent critical value sequence (dotted line) for the AH premium index (left) and the panel of 27 cross-listed companies (right). Critical values are obtained using 2000 simulations. The minimum window is 48 weeks. The shaded areas indicate periods of exuberance. 


\section{Figure 3 - Date-stamping Periods of Exuberance in A-H Price Differentials}

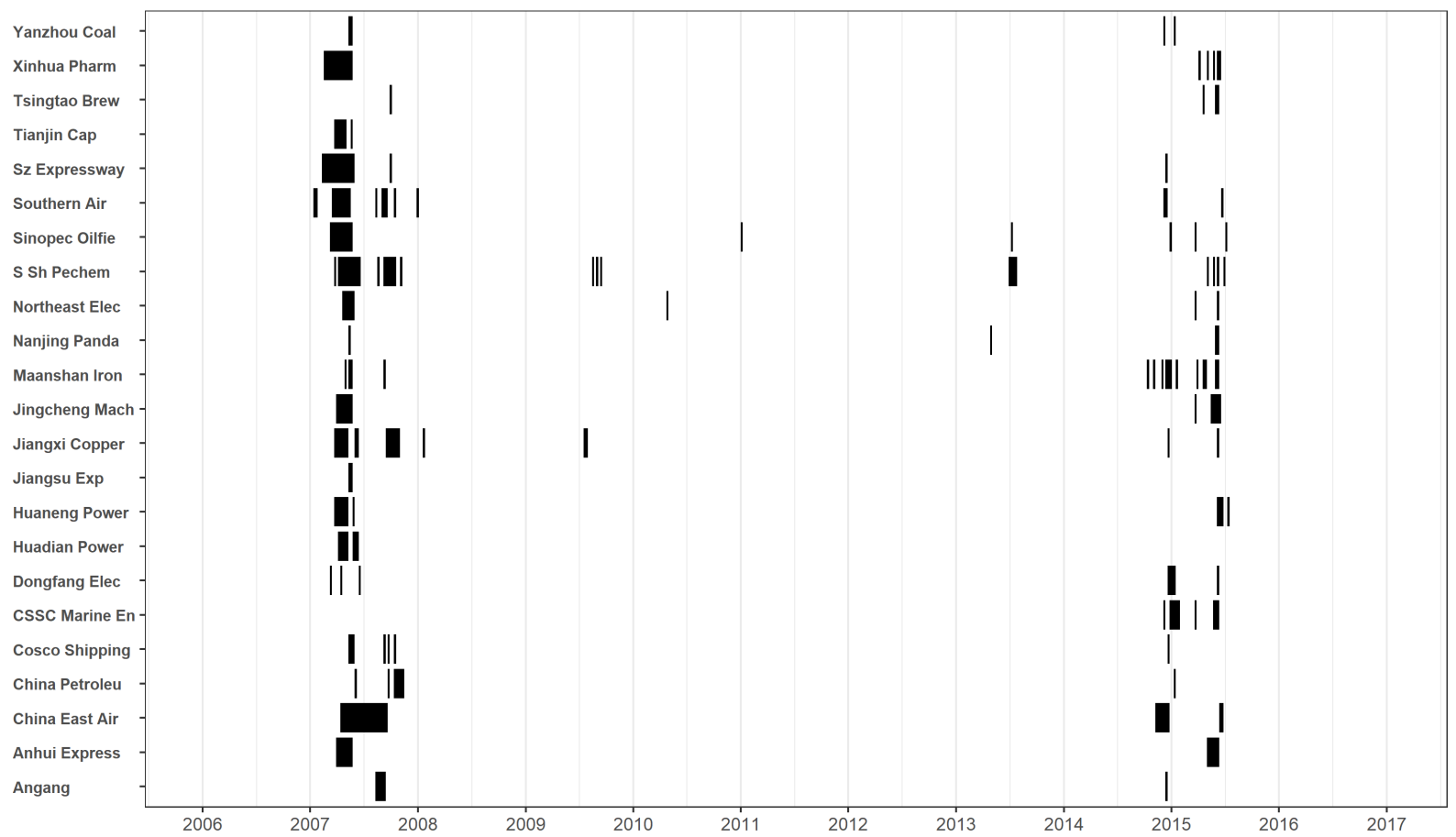

Notes: The figure shows the periods of exuberance in A-H share price differentials identified by the BSADF date-stamping strategy. 95 percent critical values are obtained using 2000 simulations. The minimum window size is 48 weeks.

Figure 4 - DATE-STAMPING PeRiods of In-SAMPle Predictability

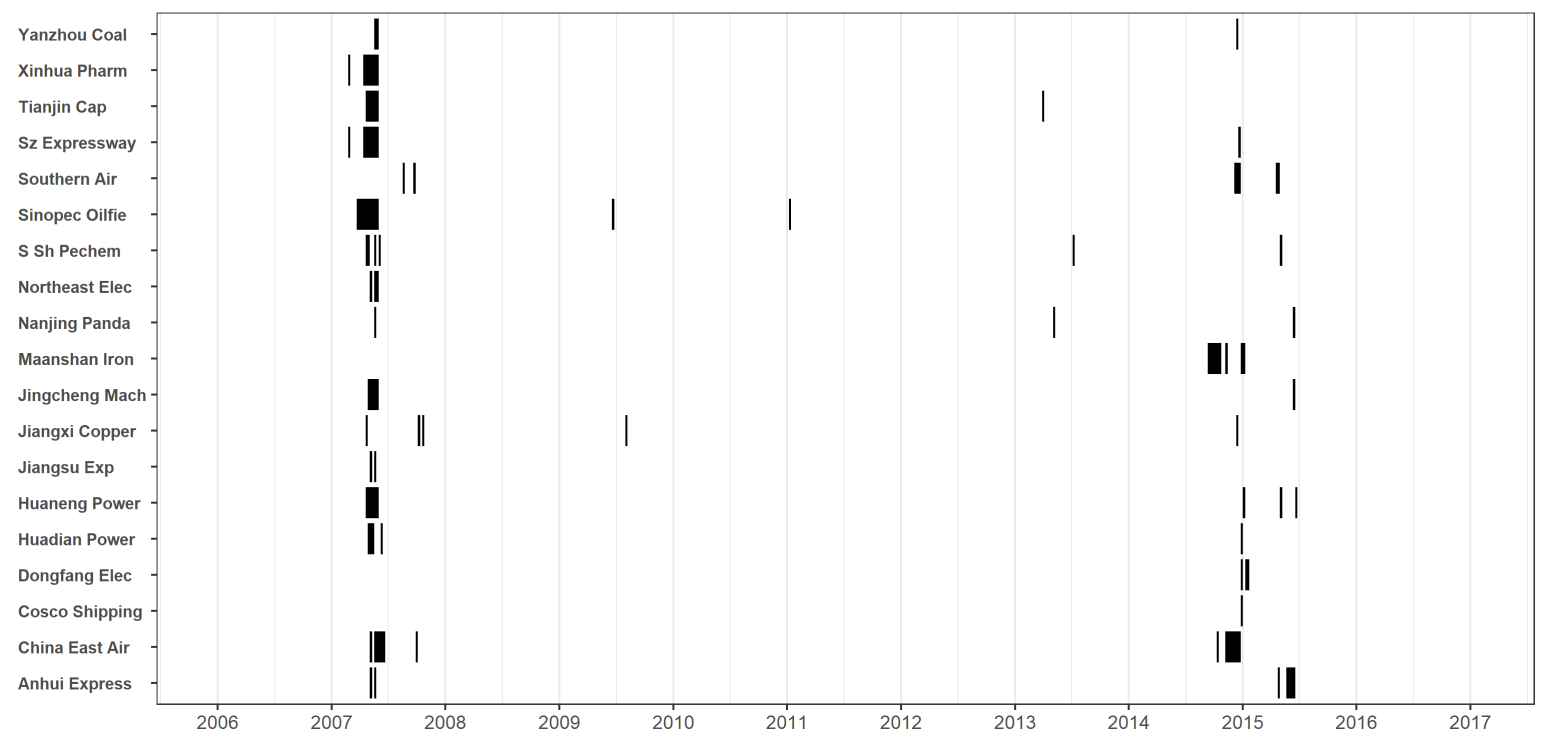

Notes: The figure shows the periods of in-sample predictability of A-share price movements identified by IVX rolling-predictive regressions. The regressor in Equation [13 is the A-H price differential. The window size is 48 weeks. 
Figure 5 - Date-Stamping Periods of Exuberance in A-ADR Price Differentials

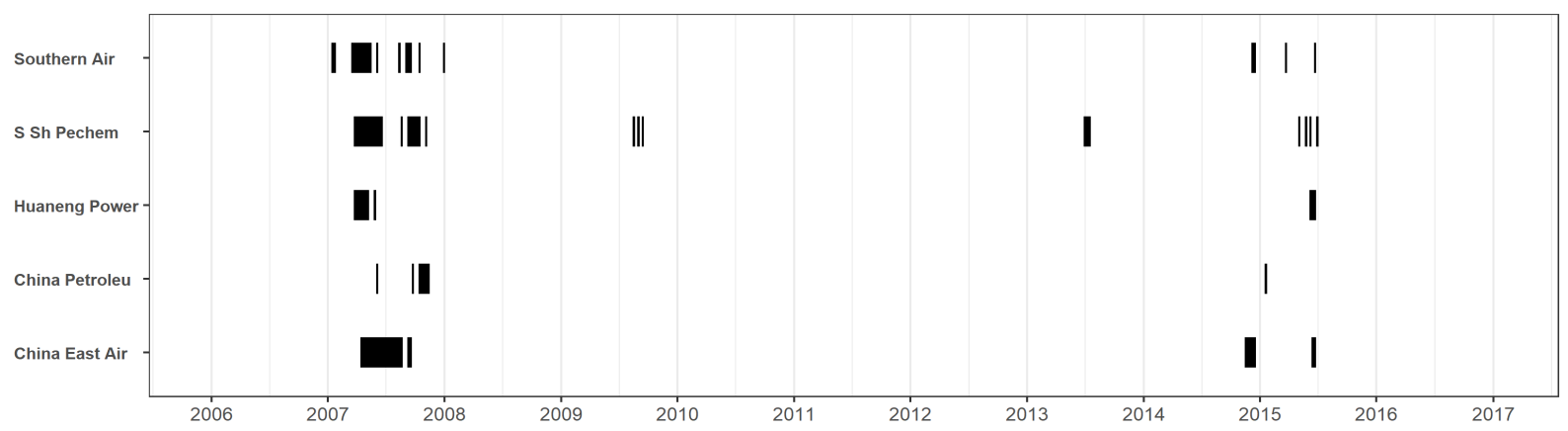

Notes: The figure shows the periods of exuberance in A-ADR price differentials identified by the BSADF date-stamping strategy. 95 percent critical values are obtained using 2000 simulations. The minimum window size is 48 weeks.

Figure 6 - DATE-STAMPing Periods of In-SAmple Predictability

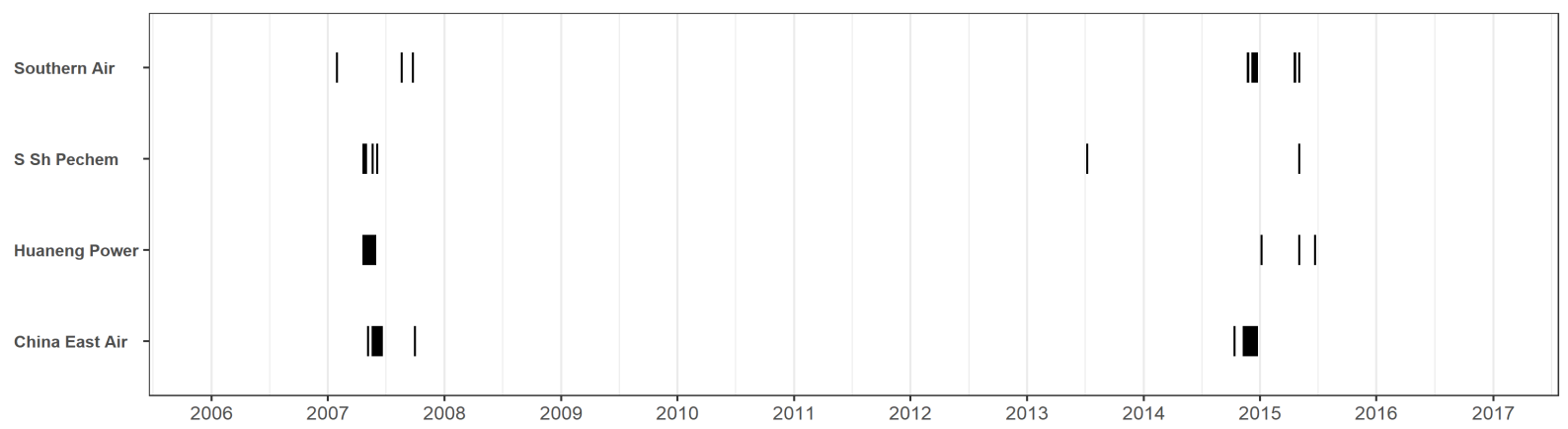

Notes: The figure shows the periods of in-sample predictability of A-share price movements identified by IVX rolling-predictive regressions. The regressor in Equation $[13$ is the A-ADR price differential. The window size is 48 weeks. 